\title{
CAZyome and Sugar Transportome Unveil Singular Aspects of the Lignocellulolytic Enzyme System of Penicillium echinulatum $2 \mathrm{HH}$
}

Alexandre Rafael Lenz ${ }^{1,3,4^{*} \dagger}$, Eduardo Balbinot ${ }^{1 \dagger}$, Nikael Souza de Oliveira ${ }^{1 \dagger}$, Fernanda Pessi de Abreu ${ }^{1 \dagger}$, Scheila de Avila e Silva ${ }^{1 \dagger}$, Marli Camassola ${ }^{2 \dagger}$, Aldo José Pinheiro Dillon ${ }^{2 \dagger}$ and Ernesto Perez-Rueda ${ }^{4 \dagger}$

\begin{abstract}
Background: The production of bioethanol using lignocellulosic feedstocks has proved to be a cutting-edge technology. However, this technology faces limitations such as cost and yield of enzymatic systems, required to degrade efficiently the polysaccharides of plant cell walls. Penicillium echinulatum $2 \mathrm{HH}$ is a widely studied ascomycete, known by its efficient cellulolytic cocktails. One strategy to improve the saccharification yields for commercial exploitation is the design of hypersecreting strains. However, molecular knowledge about the lignocellulolytic system of this specific fungus is scarce. Understanding both lignocellulolytic and sugar uptake systems is essential to obtain industrial strains with adequate efficiency for bioethanol production.

Results: We report a comprehensive in silico characterization of CAZymes and sugar transporters of $P$. echinulatum $2 \mathrm{HH}$. The CAZyome reveals an outstanding repertoire of enzymes involved in plant biomass degradation. Among them, we highlight the cellulolytic enzyme system whose genes are predominantly orthologous to $P$. oxalicum 114-2, demonstrating the high similarity of these phylogenetically related enzyme producers. We also report a LPMO-type enzyme of the AA16 family described for the first time in these fungi. In addition to the well-known high activity of $\beta$-glucosidases, we found that coding genes for the AA16, GH5-4 and $\mathrm{GH} 45$ families comprehend the main differences in the cellulolytic complexes of $P$. echinulatum $2 \mathrm{HH}$ and $P$. oxalicum 114-2, when both are compared to commercial producers. Our phylogenetic analysis of the sugar transportome suggests that $P$. echinulatum $2 \mathrm{HH}$ diversity and specificity of $\mathrm{ST}$ s include eight major families with specificity to different groups of sugars. Finally, our phylogenetic analyses enabled the identification of several iBGLs and STs potentially involved in the accumulation of intracellular cellodextrins.

Conclusions: Overall, both CAZyome and sugar transportome of $P$. echinulatum revealed new insights into the mechanisms underlying a flexible and highly functional metabolism to degrade plant biomass. Peculiarities found in our study help to highlight the cellulolytic complex of $P$. echinulatum $2 \mathrm{HH}$, contributing to the commercial ascendance of Penicillium spp. as cellulolytic enzyme producers. Furthermore, the first phylogenetic classification of STs and iBGLs shed new light into the role of these genes regarding the preferred carbon source during fungal growth. Along these lines, these iBGLs and STs comprise valuable gene targets to understand the regulatory mechanisms underlying cellulolytic enzymes and to design hypersecreting strains with adequate efficiency for bioethanol production in large-scale.
\end{abstract}

Keywords: lignocellulolytic; CAZy; sugar transporter; cellobiose; cellulase

\footnotetext{
${ }^{*}$ Correspondence: arlenz@ucs.br,alenz@uneb.br

${ }^{1}$ Laboratório de Bioinformática e Biologia Computacional, Instituto de Biotecnologia, Universidade de Caxias do Sul (UCS), Rua Francisco Getúlio Vargas, 1130, 95070-560, Caxias Do Sul, RS, BR

${ }^{3}$ Departmento de Ciências Exatas e da Terra, Universidade do Estado da Bahia (UNEB), Rua Silveira Martins, 2555, 41150-000, Salvador, BA, BR Full list of author information is available at the end of the article ${ }^{\dagger}$ Equal contributor
}

\section{BACKGROUND}

Second-generation bioethanol produced by using lignocellulosic feedstock has proved to be a cutting-edge technology in optimizing the production of biofuels. Renewable sources used for generating bioethanol exhibit a particularly rich lignocellulose content. The high cost of bioethanol production from second-generation feedstocks results from the pretreatment and enzymatic 
hydrolysis processes, required to convert this lignocellulosic biomass into monomeric sugars more rapidly and with greater yields [1]. Some Penicillium species have been highlighted due to its superiority over existing enzyme producers, especially due to the production of balanced cellulolytic cocktails rich in $\beta$-glucosidases. Consequently, these enzymatic mixtures result in improved enzymatic hydrolysis yields [2].

$P$. echinulatum is widely studied for biofuels production from lignocellulosic biomass, mainly agricultural residues, such as sugar-cane bagasse and elephant grass $[3,4,5,6]$. P. echinulatum has been studied for about 40 years, since the isolation of the $2 \mathrm{HH}$ wild-type. Longterm strain improvements resulted in the S1M29 mutant that yields an expressive increase in cellulase titers and provides a better lignocellulosic biomass hydrolysis $[7,8]$.

Filamentous fungi genome, secretome and transcriptome analyses are quite relevant for enzymatic cocktails design, particularly for biofuel production. The design of hypersecreting strains is essential to achieve adequate efficiency of enzyme mixtures, considering the established potential of $P$. echinulatum $2 \mathrm{HH}$ for the production of cellulolytic enzymes. In summary, it is necessary to understand the different strategies employed by $P$. echinulatum $2 \mathrm{HH}$ to degrade lignocellulosic biomass, enabling the enhancement of enzyme production. The ability of fungi to grow, to transport, and to ferment different types of sugars remains a major challenge for biofuels production from lignocellulosic biomass [9]. The plant lignocellulosic biomass is primarily made up of the glucohomopolysaccharide cellulose (20-50\%, w/w), hemicellulose (15-35\%, w/w) and lignin. The polysaccharides that constitute the hemicellulose include xylan, glucuronoxylan, xyloglucan, glucomannan and arabinoxylan backbones with heterogeneous side-chains. The use of monosaccharides that constitute plant biomass polymers implies their efficient hydrolysis, which is still a major technical challenge because of its recalcitrance and heterogeneity [10].

$P$. echinulatum $2 \mathrm{HH}$ was first isolated from the digestive-tract of coleoptera larvea, commonly known as furniture beetles. As the name suggests, it is known to feed on wood and has the potential to reduce wooden objects to fine dust. Moreover, Anobium punctatum larvae normally live in coarse wood debris, which are weakened and predigested fallen tree trunks, allowing the larva to move through the cracks [11]. Assuming that lignin, cellulose and hemicellulose work together to provide a structural function in plants and lignin is responsible for stiffness and rigidity [12], it can be stated that the larvae diet is basically composed by cellulose and hemicellulose, and may contain some lignin residues. In this sense, the first enzymatic production experiments with $2 \mathrm{HH}$ strain raised evolutionary speculations, suggesting a possible long-term mutualistic symbiosis between the $2 \mathrm{HH}$ strain and $A$. punctatum larvae.

Cellulose degradation is mediated by the cellulolytic enzyme system, widely used for biofuel production [13]. Besides that, different biopolymers require specific enzymatic systems for their degradation, such as starchdegrading enzymes responsible for starch degradation and xylan-degrading enzymes responsible for hemicellulose major component depolymerization. Enzymes that degrade, modify or create glycosidic bonds are known as CAZymes and are classified by the CarbohydrateActive Enzyme (CAZy) database. These enzymes are organized into different families, according to their amino acid sequence and structural similarity: i) Glycoside Hydrolases (GHs) are responsible for hydrolysis and / or rearrangement of glycosidic bonds; ii) Glycosyl Transferases (GTs) are responsible for the formation of glycosidic bonds; iii) Polysaccharide Lyases (PLs) perform non-hydrolytic cleavage of glycosidic bonds; iv) Carbohydrate Esterases (CEs) hydrolyze carbohydrate esters; v) Auxiliary Activities (AAs) are redox enzymes that act synergically with other CAZymes; and vi) Carbohydrate Binding Modules (CBMs) promote the adhesion of the enzyme to the carbohydrate [14].

The cellulolytic system comprises a variety of enzymes that act synergistically: (i) cellobiohydrolases (CBHI) (GH7) cleave at the reducing ends of the cellulose chain; (ii) cellobiohydrolases (CBHII) (GH6) cleave at the non-reducing ends of the cellulose chain; (iii) endoglucanases (EGL) (GH5, GH7, GH12 and GH45) cleave in amorphous cellulose regions; (iv) lytic polysaccharide monooxygenases (LPMO) (AA9 and AA16) can act on both crystalline and less-crystalline regions; (v) cellobiose dehydrogenases $(\mathrm{CDH})$ (AA3-1 and AA8) act on cellobiose oxidation, producing electrons that help the depolymerization of cellulose to be catalyzed by LPMOs; and (vi) the oligosaccharides are further hydrolysed to D-glucose by $\beta$-glucosidases (BGL) (GH3) $[12,15,13,10,16]$. In addition to the widely studied GHs, the cellulolytic complex includes some enzymes with auxiliary activities (AAs). These enzymes act in a synergistic process (CDH-LPMO) in the oxidizing reductive cleavage of the cellulose chain [15]. Auxiliary activity enzymes help to reduce the enzyme dosage required for biomass degradation and, therefore, have become important enzymes found in recent commercial cellulases formulations [17].

The production of plant cell wall degrading enzymes, cellulases, hemicellulases, ligninases and pectinases, is regulated mainly at the transcriptional level in filamentous fungi. Gene expression of these enzymes is 
regulated by various environmental and cellular factors, some of which are common while others are speciesspecific or enzyme class-specific. These genes are inducible in presence of the carbon source or molecules derived from the carbon source, whereas repression occurs under growth conditions where the production of these enzymes is not necessary, such as in presence of glucose. Along these lines, it has been shown that cellulolytic enzyme expression is induced by cellobiose in many species of fungi, regarding cellobiose is the primary end product generated from cellulose degradation by cellulases [18]. Recent research results support that accumulation of intracellular cellodextrins (mainly cellobiose) may raise cellulases secretion by a cascade signaling pathway in P. oxalicum [19] and Neurospora crassa $[20]$.

Filamentous fungi are able to transport a wide diversity of sugars by transmembrane proteins. The vast majority of Sugar Transporters (STs) characterized so far, belong to the subfamily (PF00083) of the major facilitator superfamily (MFS). Members in this subfamily include various STs, which are responsible for the binding and transport of various carbohydrates, organic alcohols, and acids [21, 22]. Among these sugars, filamentous fungi are able to transport disaccharides such as cellobiose into the cell through specific transporters. Cellobiose and other cellodextrins can act as signal transducers in two ways: i) cellodextrins are transported into cells activating intracellular sensors, and ii) extracellular cellodextrins activate plasma membrane sensors, such as transporter-like proteins or protein-coupled $\mathrm{G}$ receptors [23].

Recently, the whole genome sequences (WGS) of both 2HH wild-type and S1M29 mutant were deposited at GenBank, allowing studies to discover novel features of the lignocellulolytic enzyme system of $P$. echinulatum. These WGS provided evidence that $2 \mathrm{HH}$ wild-type strain is closely related to $P$. oxalicum, leading to a taxonomic revision study of this fungus. In this study, we explore the genomic content of this notable fungus to discover novel features of the lignocellulolytic expression mechanisms, including the characterization of CAZymes and STs involved in the accumulation of intracellular cellodextrins. We also link experimental results of cellulase enhancement secretion from established cellulase producers to $P$. echinulatum $2 \mathrm{HH}$, by analyzing amino acid sequences similarities and their likely roles.

Here, we analyzed the genes that constitute the cellulolytic enzyme system of $P$. echinulatum $2 \mathrm{HH}$ using a comparative genomic approach. Besides, P. echinulatum $2 \mathrm{HH}$ phylogenetic adjacency to $P$. oxalicum 114-2 enabled genomic comparisons to identify singularities in the lignocellulolytic enzyme system of these two well-known enzyme producers. Characterization of CAZymes and STs also provided new evidences to elucidate the adaptation of $P$. echinulatum $2 \mathrm{HH}$ to the coleoptera larvae diet during a potential long-term mutualistic symbiosis. Additionally, our in silico approach allowed the discovery of new gene targets and suggests a path to engineer $P$. echinulatum $2 \mathrm{HH}$ for industrial use. Finally, our results point to a broad number of genes involved on cellulolytic expression mechanisms, revealing new targets to design hypersecreting strains.

\section{RESULTS AND DISCUSSION}

\section{$P$. echinulatum CAZyome}

Among all CAZymes annotated in P. echinulatum proteome and detailed in Additional file A01.1, we highlight the protein encoding-genes for the cellulolytic enzyme system in Table 1. Cellulase mixtures of Penicillium spp. are known to be rich in $\beta$-glucosidase [2], they are found in GH1 and GH3 families in P. echinulatum $2 \mathrm{HH}$. Those proteins belonging to GH1 are probably intracellular enzymes, whereas five of nine GH3 $\beta$-glucosidases contain a signal peptide and are probably secreted into the medium. Furthermore, all cellobiohydrolases also contain a signal peptide, one of GH6 family and two of GH7 family. In addition, endo-1,4- $\beta$-D-glucanases are found in GH5-4, GH5-5, GH5-22, GH7, GH12 and GH45 families, where GH5-22 family is probably an intracellular enzyme, whereas all others contain a signal peptide. Considering AA enzymes, four LPMOs of AA9 family, the LPMO of AA16 family and the $\mathrm{CDH}$ enzyme of AA3-1 family contain a signal peptide, with the exception of the $\mathrm{CDH}$ enzyme of AA8 family. These AAs act synergically with the GHs, playing a crucial role in cellulose degradation system. The LPMO-type enzyme of AA16 family acts on cellulose with oxidative cleavage at the $\mathrm{C} 1$ position of the glucose unit [16]. In this study we identified this enzyme for the first time in $P$. echinulatum $2 \mathrm{HH}$ and P. oxalicum 114-2.

Among the putative cellulases, only EGL1 has been cloned, characterized and heterologous expressed [24]. This characterization showed that EGL1 optimal temperature is $60{ }^{\circ} \mathrm{C}$ and the optimal activity occurs over a broad $\mathrm{pH}$ range (5-9). Furthermore, the EGL1 secreted by a Pichia pastoris recombinant also showed high thermostability $(84 \%$ of residual activity after $1 \mathrm{~h}$ of pre-incubation at $70{ }^{\circ} \mathrm{C}$ ) and calcium exerted a strong stimulatory effect over EGL1 activity [24].

Another putative EGL (PECH_006176/PECM_002589) was predicted to contain a near C-terminal CBM_X2 domain (Pfam ID: PF03442, InterPro ID: IPR005102) in addition to a CBM1 (Pfam ID: PF00734, InterPro ID: IPR000254) and a GH5-4 typical catalytic domain 
(Pfam ID: PF00150, InterPro ID: IPR001547). Homology search suggested that proteins containing cellulase catalytic domain followed by CBM_X2 were present in many fungal species like PdCel5C (PDE_09969) in $P$. oxalicum [25], Cel5C (PMG11_08470) in P. brasilianum, Endoglucanase B (EN45_076530) in P. chrysogenum and (PENSUB_1985) in P. subrubescens. It is important to highlight that GH5-4 catalytic domain is not found in cellulolytic complexes of Trichoderma reesei and N. crassa.

Several CAZymes contains accessory non-catalytic domains (e.g.: CBMs). InterPro, PROSITE, Pfam and dbCAN2 were used to refine CBM predictions and the results are presented in Table A01.2. Specifically, we found 58 proteins containing at least one CBM domain, including 24 proteins with a CBM1 domain targeting cellulose. The main CBM1-containing cellulases are featured in Table 1. In addition to the cellulolytic enzymes of GH families 5, 6, 7, 45 and AA9, CBM1 was also observed in association with different types of catalytic domains from CE2 family and GH families 10, 11, 26, 30, 43 and 62. Furthermore, CBM1 was observed as associated with CBM63 domain, also targeting cellulose in a swollenin encoding-gene. We also found an expansin encoding-gene, containing a CBM63 domain. Many expansin-like proteins have been reported and demonstrated to bind and act on cellulosic networks. Some of them have shown to act synergistically with cellulases and xylanases [26].

P. echinulatum $2 \mathrm{HH}$ exhibit a broad profile of plant biomass degrading enzymes (detailed in Additional file A01.1), including a variety of enzymes required for xylan degradation: endo- $\beta-1,4$ xylanases (GH10, GH11), $\alpha$-L-arabinofuranosidases (GH43, GH51, GH54, and GH62), $\beta$-xylosidases (GH43 and GH3), acetylxylan esterases (CE1, CE5), $\alpha$-glucuronidase (GH67), and ferulic acid esterases (CE1). It also contains enzymes required for xyloglucan degradation, including $\alpha$-xylosidases (GH31), $\beta$-galactosidases (GH2 and GH35), $\alpha$-L-arabinofuranosidases (GH43, GH51, GH54, and GH62) and $\alpha$-fucosidases (GH29 and GH95). Yet, it includes enzymes required for galactomannan degradation: endo- $\beta$-1,4-mannases (GH5-7) and $\alpha$ galactosidases (GH27, GH36). A wide range of enzymes necessary for efficient degradation of pectin was also observed, including polygalacturonases and rhamnogalacturonases of GH28 family, pectin and pectate lyases (PL1), and rhamnogalacturonan lyases (PL4), as well as pectin esterases (CE8) and rhamnogalacturonan acetylesterases (CE12). Enzymes that function on RG-I side chain substitutions include arabinanases (GH43, GH93), arabinosidases / $\alpha$-arabinofuranosidases (GH43, GH51, GH54, and GH62), galactanases (GH16, GH30 and GH53), $\alpha$ - and $\beta$-galactosidases (GH2, GH27,
GH35, GH36, and GH43), $\beta$-glucuronidases (GH67, and GH79), and feruloyl esterases (CE1).

In summary, the CAZyome characterization confirms the natural potential of $P$. echinulatum $2 \mathrm{HH}$ for the production of cellulolytic mixtures. Considering that $P$. echinulatum $2 \mathrm{HH}$ is known to produce a vast range of CAZymes, primarily cellulases and xylanases, previously described by secretome analysis [7]. These results provide an important step in the molecular understanding of this microorganism, allowing strain improvements using advanced techniques and further elevating the importance of the genus Penicillium in biotechnology for biofuels.

\section{CAZymes as evolutionary markers}

Whole genome sequences of $2 \mathrm{HH}$ wild-type strain, deposited recently at GenBank, provided evidence that $2 \mathrm{HH}$ is closely related to $P$. oxalicum, leading to a taxonomic revision study of this fungus. The phylogenetic proximity between $P$. echinulatum $2 \mathrm{HH}$ and $P$. oxalicum 114-2 and the orthology of genes belonging to the cellulolytic system (detailed in Additional file A01.1) denote that the cellulolytic system of $P$. echinulatum $2 \mathrm{HH}$ and $P$. oxalicum 114-2 are highly similar. We found the respective orthologous in $P$. oxalicum 114-2 for almost all cellulolytic genes of $P$. echinulatum $2 \mathrm{HH}$.

The isolation method of $2 \mathrm{HH}$ strain hypothesizes a potential natural adaptation for the secretion of cellulolytic enzymes, as a possible adaptation to A. punctatum larvae diet as the only growth condition available for the fungus. To date, this evolutionary hypothesis was supported only by the mixture of cellulases secreted by the $2 \mathrm{HH}$ strain, which provides an effective enzymatic formulation for complete saccharification of plant residues rich in cellulose and hemicellulose [7]. This hypothesis encourages the search for new insights into the uptake of carbon sources available in the environment.

In order to understand evolutionary relationships, we analyzed the differences in the CAZyome composition of $P$. echinulatum $2 \mathrm{HH}$ and $P$. oxalicum 114-2. First, we analyzed CAZymes that showed low transcription level in P. oxalicum 114-2 [27] and their respective orthology in $P$. echinulatum. In $P$. oxalicum, PDE_05193 is an endo-1,4- $\beta$-D-glucanase with a signal peptide and it is orthologous of (PECH_006981/PECM_005047) in $P$. echinulatum. The secretion profile of $P$. oxalicum does not show secreted protein ratio for PDE_05193 and the transcription levels in CW medium is very low [27]. When we aligned the nucleotides of $P$. oxalicum 114-2 and $P$. echinulatum $2 \mathrm{HH}$, it was possible to observe an insertion in $P$. echinulatum $2 \mathrm{HH}$, exactly where should be the correct start codon of this gene, suggesting that this gene may have been disabled by mutations. 
In the same way, extracellular $\beta$-glucosidase BGL3 (PDE_01277) of $P$. oxalicum 114-2 did not show activities on both pNPG and salicin in vitro and its role is not yet known [19]. In $P$. echinulatum $2 \mathrm{HH}$ we have not found the ortholog of this $\beta$-glucosidase of GH1 family. To confirm the absence of this ortholog, we performed a syntenic comparison of the genome region that was supposed to contain the orthologous of PDE_01277 in P. echinulatum 2HH. We observed that this part of the sequence was missing, comprising the location of both PDE_01277 and PDE_01278 orthologs. Although, nearby synteny is preserved, both before (PDE_01276) and after (PDE_01278), exhibiting their respective orthologs (PECH_007174 and PECH_007175) in $P$. echinulatum $2 \mathrm{HH}$.

In contrast, by searching for orthologs in $P$. brasilianum, $P$. subrubescens and $P$. chrysogenum, we found the respective orthologs of both endo-1,4- $\beta$-D-glucanase and $\beta$-glucosidase of $P$. oxalicum 114-2. These orthologs in related Penicillium spp. suggest that the absence of both genes are particular evolutionary characteristics of $P$. echinulatum $2 \mathrm{HH}$. It is remarkable that these two genes are also the only differences in the proteins containing signal peptide, when we compare the cellulolytic complexes of $P$. echinulatum $2 \mathrm{HH}$ and $P$. oxalicum 114-2. An adaptive characteristic, such as the ability to survive within a specific host, may culminate in "conditionally dispensable" genes, reflecting their importance in some, but not all, growth conditions. Gene loss during the evolution can be an adaptive evolutionary force that is especially effective when organisms are faced with abrupt environmental challenges [28].

Additionally, orthology analysis revealed other important CAZymes of $P$. oxalicum 114-2 for which the respective orthologs were not found in $P$. echinulatum 2HH, including: (PDE_02801 - GH2) $\alpha$-glucuronidase, (PDE_02413 - GH3) xylan 1,4- $\beta$-xylosidase, (PDE_01949 - GH79) $\alpha$-glucuronidase, (PDE_02902 - GH88) d-4,5 unsaturated $\beta$-glucuronyl hydrolase, (PDE_02128 AA1) multicopper oxidase, (PDE_01302 - CE2) acetyl xylan esterase and (PDE_03849 - CE16) acetylesterase. Furthermore, it is also noticeable that $P$. oxalicum 1142 proteome does not include enzymes of GH29 family, while $P$. echinulatum $2 \mathrm{HH}$ contains one $\alpha$-fucosidase. The proteome of $P$. echinulatum includes also an additional intracellular $\beta$-glucosidase (iBGL)-encoding gene (PECH_004285/PECM_001151) when compared to $P$. oxalicum 114-2. This additional $\beta$-glucosidase is orthologous to Cel3C in T. reesei Qm6a and to PMG11_03092 in $P$. brasilianum MG11. Moreover, P. echinulatum $2 \mathrm{HH}$ showed four additional $\alpha$-L-rhamnosidase coding genes of GH78 family, when compared to $P$. oxalicum 114-2. A plausible reason for the existence of these additional genes could be the abundance of undigested plant compounds in the larvae gut, considering that $\alpha$-lrhamnose and fucose are found in plants as components of polysaccharides, such as pectins.

The coleoptera larvae diet, mainly composed of cellulose, hemicellulose and residues of lignin from decayed wood [11], led us to hypothesize the presence of environment-specific adaptations in P. echinulatum $2 \mathrm{HH}$ to degrade these biopolymers. Along these lines, we investigate a specific set of enzymes required to degrade wood, comparing $P$. echinulatum $2 \mathrm{HH}$ and $P$. oxalicum 114-2. We included 18 families of peroxidases and CAZymes in our analyses, as it was previously suggested [29]. Table 2 shows the number of encoding genes of each enzyme family, which were organized into three major groups: oxidoreductases related to the degradation of lignin or lignin-like compounds, CAZys active on polysaccharide main chains; and other CAZys related to wood decay.

Fewer oxidoreductases encoding-genes of AA1 family and HTP-type could be explained by the larvae diet, which probably does not comprise unaffected lignin, but contains lignin-related compounds. Surprisingly, an encoding-gene of dye-decolorizing peroxidase (DyP) was found in P. echinulatum $2 \mathrm{HH}$. This family of hemecontaining peroxidases is active on lignin-related compounds and contains important properties for lignocellulose biorefineries [30]. Apparently, this enzyme is not a particular adaptation of $P$. echinulatum $2 \mathrm{HH}$, considering that the orthologs of this DyP peroxidase were found in $P$. brasilianum, $P$. subrubescens and $P$. chrysogenum, with the exception of $P$. oxalicum 114-2.

In summary, the major differences of $P$. echinulatum $2 \mathrm{HH}$ in relation to $P$. oxalicum 114-2 include: i) fewer encoding-genes for oxidoreductases of AA1 family and HTP-type, contrasting with an additional encoding-gene for a DyP peroxidase, which all related to lignin compounds degradation; ii) one less endo1,4 - $\beta$-glucanase of GH5 family and one less extracellular $\beta$-glucosidase of GH1 family, where both enzymes showed low transcription levels in P. oxalicum 114-2; iii) four additional $\alpha$-L-rhamnosidases of GH78 family, comprising a remarkable range of enzymes related to pectin degradation; iv) one less $\beta$-xylosidase and one additional iBGL of GH3 family, which is ortholog of Cel3C in T. reesei; and v) one less acetyl-xylan esterase of CE16 family, one additional endomannanase of GH5-7 family and one additional $\alpha$-fucosidase of GH29 family. Our results reinforce the hypothesis that a potentially host-symbiont association may lead to environment-specific adaptations in the symbiont (fungus), particularly due to the host (insect larvae) diet, although it is still a hypothesis. $P$. echinulatum $2 \mathrm{HH}$ and $P$. oxalicum 114-2 may have a very close common ancestor and this is a remarkable finding that might 
grant a status to $P$. echinulatum $2 \mathrm{HH}$ on the global market of enzymes producers, particularly owing to its potential natural evolution for cellulase production.

\section{Comparative analysis of Plant Biomass Degrading CAZymes (PBDC) in related fungi}

We performed a comparative analysis of the number of CAZy coding proteins, which are related to the degradation of plant biomass, and which also contain signal peptide. First, we identified putative CAZymes, then each one was classified according to its connection to plant biomass degradation, as it was previously suggested [31]. Finally, we crossed both PBDC and signal peptide predictions. Our results provide a comprehensive comparative analysis of plant biomass degradation profile between twelve filamentous fungi species. The stacked barplot (Fig. ) shows the distribution of potentially extracellular CAZymes (number of proteins) involved in degradation of plant biopolymers. Complementary information about PBDC predictions are available in Additional file A02. Comparative studies like this one, contribute with the identification of nature and peculiarities for each species and how each one can be used for commercial enzymatic production.

As can be observed in the stacked barplot (Fig. ), when we totalize the number of proteins in all CAZy classes, the total number of PBDC in analyzed $A s$ comycetes and also between the Penicillium species varies greatly. Our results revealed an expressive higher number of PBDC for P. subrubescens, totalizing 181 proteins. Aspergillus oryzae also displays a wide range of PBDC, being the two fungi to outpace the 180 proteins, while $P$. digitatum includes only 71 proteins. In contrast, $P$. echinulatum and $P$. oxalicum include an average number of PBDC, comprising 125 and 121 proteins, respectively. Although the number of PBDC is not a key factor for efficient breakdown of plant biomass, our comparison shows the potential for enzyme secretion in relevant filamentous fungi.

A previous study observed CAZy families that were present in P. chrysogenum and Aspergillus niger but not in $T$. reesei [32]. These enzymes comprise CE8 and CE12 families whose proteins encode for pectin methylesterase and rhamnose acetylesterase activities, respectively. Also, PL1-7 and PL4-1 families that encode for pectate lyase and rhamnogalacturonan lyase activities respectively, and endo- $\alpha-1,5$-L-arabinosidase from GH43-6 family. In our study we observed that the same families were present in almost all analyzed species but not in $T$. reesei, indicating that $T$. reesei does not include enzymes with these activities. Except for $N$. crassa which also does not include GH43-6 enzymes. In summary, $T$. reesei provides a narrow range of enzymes for pectin degradation when compared to the other fungi.
A larger difference was observed in $P$. echinulatum $2 \mathrm{HH}$ when compared to other Penicillium species. Most of this difference can be attributed to GH11, GH43 and AA9, which account for $19 \mathrm{PBDC}$ in $P$. echinulatum, 16 in $P$. oxalicum, 12 in $P$. chrysogenum, 16 in $P$. brasilianum, 29 in $P$. subrubescens and only 2 in $P$. digitatum. Enzymes of these families are mostly related to the degradation of hemicellulose and cellulose, including xylanases, xylosidades, arabinofuranosidases and LPMOs. As already mentioned, $P$. echinulatum $2 \mathrm{HH}$ and $P$. oxalicum 114-2 showed a quite similar profile of putative cellulolytic enzymes, leading to their comparison with other filamentous fungi to discover peculiarities of cellulolytic enzyme profiles. In this context, we highlight the ability of these two fungi to produce effective cellulolytic cocktails. We made interesting discoveries by reducing the analysis scope to putative proteins of the cellulolytic system that carry signal peptide (Fig. ).

In $T$. reesei, despite the regular number of $\beta$ glucosidase putative proteins, it is known that the low $\beta$-glucosidase activity of the cellulolytic complex leads to inefficiency in biomass degradation, requiring genetic engineering for secretion enhancement of this enzyme [33]. Additionally, the conservation of LPMO-type enzyme (AA16) in Aspergilli and Penicillia analyzed is notable, while this enzyme family was not found in $\mathrm{Neu}$ rospora and Trichoderma genomes. Another interesting finding comprises putative cellulases of GH45 family. Here, we demonstrated that only four of the twelve filamentous fungi investigated possess GH45 proteins containing signal peptide. Lastly, GH5-4 typical catalytic domain was not found in the cellulolytic complex of T. reesei, N. crassa and A. niger.

In summary, our results showed that both $P$. echinulatum $2 \mathrm{HH}$ and $P$. oxalicum 114-2 enclose a quite similar profile of PBDC. Cellulolytic activities of AA16, GH5-4 and GH45 deserve attention when it comes to understanding their roles in the cellulose degradation system of $P$. echinulatum $2 \mathrm{HH}$ and $P$. oxalicum 114-2. Considering that these enzymes comprehend the main differences in the cellulolytic complexes, when both are compared to commercial producers. The peculiarities found in our study may contribute to highlight $P$. echinulatum $2 \mathrm{HH}$ and $P$. oxalicum 114-2 cellulolytic complexes, contributing to the commercial ascendance of these two fungi. In addition to the high level of extracellular $\beta$-glucosidase activity, our results help to support the commercial application of $P$. echinulatum $2 \mathrm{HH}$ for cellulolytic enzymes production.

\section{Cellulolytic system expression induced by cellodextrins}

Cellodextrins are saccharide polymers of varying length (two or more glucose monomers) resulting from 
cellulolysis, the breakdown of cellulose. The primary end product generated from cellulose degradation is disaccharide cellobiose. Cellodextrin classification occurs by its degree of polymerization (DP) including different saccharide polymers, such as cellobiose (DP2), cellotriose (DP3), cellotetraose (DP4) and so forth. Research results support the existence of a cascade signaling pathway conserved in filamentous fungi [18]. This pathway acts when cellobiose or other cellodextrins accumulates into the cell, raising the secretion of cellulases. In this context, intracellular accumulation of cellodextrins can occur in two ways: i) by low activity of iBGLs, which reduces the hydrolysis of cellodextrins to D-glucose $[19,34]$; and ii) by the high expression of STs, which are able to transport cellodextrins from the medium into the cell $[20,35]$. In order to discover the features behind this cellodextrin induction system in $P$. echinulatum $2 \mathrm{HH}$, we performed several genomic analyses including iBGLs and STs, as presented below.

\section{Intracellular $\beta$-glucosidases (iBGLs)}

Phylogenetic analyses were performed using two datasets containing 19 and 32 iBGLs sequences, respectively for GH1 and GH3 families. The GH1 dataset includes 3 putative iBGLs of $P$. echinulatum $2 \mathrm{HH}$, 13 putative iBGLs from related fungi, as well as, 3 BGLs of Arabidopsis thaliana used as outgroup. The GH3 dataset includes 4 putative iBGLs of $P$. echinulatum $2 \mathrm{HH}, 26$ putative iBGL sequences of the related fungi, as well as, 2 BGLs of $A$. thaliana used as outgroup. Detailed information of iBGLs is available in the Additional file A03. Fig. shows the phylogenetic classification of iBGLs, comprising enzymes of GH1 (a) and GH3 (b) families. The roles of proteins highlighted in bold in both trees were verified and may provide evidence of likely conserved roles in filamentous fungi.

In T. reesei, CEL1a and CEL1b iBGLs may not participate directly into cellobiose hydrolysis, however they may contribute to the accumulation of cellobiose as signal inducers. CEL1a plays an important role in cellulase induction in $T$. reesei, since the cel1a single-nucleotide mutation in strain PC-3-7 resulted in high cellulase expression on cellobiose [36, 37, 34]. In T. reesei, CEL1a and CEL1b were also functionally equivalent in mediating the induction of cellulase genes by lactose and the simultaneous absence of these iBGLs abolished cbh1 gene expression. Still in T. reesei, CEL1a protein and its glycoside hydrolytic activity were indispensable for cellulase induction by lactose. Intracellular BGLmediated lactose induction is further conveyed to XYR1 to ensure the efficiently induced expression of cellulase genes [37].

Moreover, several studies were carried out involving iBGLs of GH3 family in T. reesei. Deletion of bgl3i gene significantly increased cellulase activities, it had no influence on fungal growth though. Deletion of bgl3i also enhanced transcription levels of CEL1a, CEL1b and XYR1 regulator, which are all crucial for lactose induction in T. reesei [38]. Still in T. reesei, $\Delta$ cel3c mutant had no significant influence on the expression of secreted proteins [39], while dysfunction of cel3d resulted in higher secretion of cellulases [33].

In $N$. crassa, individual BGL deletion strains $(\Delta g h 1$ 1, $\Delta$ gh3-3, or $\Delta g h 3-4)$ did not showed a significant induction of major cellulase genes, whereas a $\Delta g h 1$ 1 $\Delta g h 3$-3 double deletion mutant showed some cellulase gene induction. However, a strain carrying deletions for all three BGL genes ( $\Delta g h 1-1, \Delta g h 3-3$, and $\Delta g h 3-4)$ resulted in a strain that produces higher concentrations of secreted active cellulases on cellobiose [40]. Still in $N$. crassa, double BGL deletion strain $\Delta g h 3-2 \Delta$ gh3-5 had similar intracellular activity as the wild-type. These two BGL genes do not contribute to BGL activity production, while GH3-6 is the main responsible for intracellular BGL activity [41].

In P. oxalicum 114-2, BGL2 (PDE_00579) is the major iBGL and was found to be dependent on ClrB at the transcription level. The deletion of bgl2 facilitates the synergistic expression of cellulase genes. Lack of this iBGL facilitates the accumulation of intracellular cellodextrins, which can trigger signaling cascades that include expression of cellulase genes [42, 19].

In $P$. echinulatum, protein sequence alignments of BGL2 orthologs between S1M29 mutant (PECM_002864) and 2HH wild-type (PECH_005648), revealed a single amino acid substitution (D194P), which occurred in the major iBGL of GH1 family. Although several mutations have been identified, this mutation is probably the major source for cellulase hyperproduction by the S1M29 mutant. Despite amino acid substitution not affecting BGL2 catalytic domain in P. echinulatum S1M29, a single amino acid substitution could negatively affect the enzyme or reduce its activity, as occurred in BGL2 ortholog of T. reesei [34].

In summary, the influence of iBGLs on the induction of cellulolytic enzyme systems in filamentous fungi is undeniable. However, related fungi results report the complexity and specificities of each species. All iBGLs found in $P$. echinulatum $2 \mathrm{HH}$ are highlighted with blue stars in the phylogenetic trees, which allows opportunities to figure out molecular mechanisms underlying the regulation of cellulolytic enzymes secretion. Therefore, we suggest these highlighted genes as potential engineering targets, aiming to improve the expression of cellulolytic enzymes in P. echinulatum $2 \mathrm{HH}$.

\section{Sugar transporters (STs)}

Sugar transportome of $P$. echinulatum $2 \mathrm{HH}$ includes 64 putative ST encoding genes, found by searching 
the conserved ST domain (PF00083) on proteome. We also found considerable diversity in the numbers of PF00083-containing proteins in the fungi investigated, with more than three-fold differences between related species. Our results are consistent with the Aspergillus phylogenetic study of STs [43]. The largest and smallest numbers of PF00083-containing proteins correspond to P. subrubescens (116) and N. crassa (35), respectively. Even species from the same Penicillium section do not have similar numbers of loci, such as LanataDivaricata where $P$. oxalicum includes 59 genes and $P$. subrubescens includes 116 genes.

Furthermore, a phylogenetic analysis was performed using a dataset containing 200 ST sequences, including 64 putative STs of $P$. echinulatum $2 \mathrm{HH}, 85$ putative ST sequences of $A$. niger CBS 513.88 [22], 44 ST protein sequences of related fungi reported in literature, as well as, $7 \mathrm{STs}$ of $A$. thaliana used as outgroup. Detailed information of STs is available in the Additional file A03. Fig. shows the outcome tree representing the phylogenetic classification of STs, where nine different clades, supported by bootstrap values above $70 \%$, are clearly distinguished. Our results are accordant with previous phylogenetic studies of STs [22, 43]. Putative sugar specificity to each clade were suggested based on the previously reported properties of the STs included in the phylogenetic tree.

With the exception of unknown STs highlighted in red, we numbered the clades coursing the tree counterclockwise. The first clade contains $11 \mathrm{STs}$ of $P$. echinulatum $2 \mathrm{HH}$ and 9 known cellodextrin/lactose transporters from related fungi. This clade represents the most important group of STs for understanding the cellodextrin induction system in $P$. echinulatum $2 \mathrm{HH}$. Previous studies and established functions of these STs in related fungi, particularly in P. oxalicum, help to clarify and provide insights on the influence of cellodextrin transporters in the cellulolytic induction system. In $P$. oxalicum, overlapping activity of isoproteins was observed between cellodextrin transporters $(c d t C, c d t D$ or $c d t G)$. Deletion of a single gene resulted in no observable effect on cellulase expression. Nonetheless, simultaneous deletion of $c d t C$ and $c d t D$ resulted in remarkable decrease in cellobiose consumption and low growth on cellulose, resulting also in lower extracellular activity of cellulases. Besides, overexpression of cellodextrin transporter genes $(c d t C, c d t D$ or $c d t G)$ improved cellulase production in $P$. oxalicum mutants, with the highest fold changes in $c d t G$ overexpressed mutant [35]. Orthologous of these three cellodextrin transporters $(c d t C, c d t D$ or $c d t G)$ were found in $P$. echinulatum 2HH: PECH_005610, PECH_006659 and PECH_005330, respectively.
In Aspergillus nidulans, CltA is a cellobiose-specific transporter, while CltB/LacpB is able to transport cellobiose and lactose. However, this protein is a cellulose signaling sensor rather than a cellobiose transporter [23]. Still in A. nidulans, deletion of $\operatorname{cltB} / \operatorname{lacp} B$ resulted in reduced growth and extracellular cellulase activity, indicating that cellulose and lactose catabolic systems operate with common components. Yet, deletion of cltA showed no significant effect on cellulase expression in the presence of cellobiose [44]. In P. echinulatum $2 \mathrm{HH}$, cltA was also identified as orthologous to PECH_006659, while cltB/lacpB is also an ortholog of PECH_005610. P. echinulatum 2HH appears to lack orthologs of lacpA (high-affinity lactose permease) of $A$. nidulans, reinforcing the hypothesis that lactose is not among the preferred carbon sources of $2 \mathrm{HH}$ strain. Previous experiments have shown reduced extracellular cellulase activity in lactose medium by $9 \mathrm{~A} 02 \mathrm{~S} 1$ mutant, obtained from the $2 \mathrm{HH}$ strain [45]. In T. reesei, Crt1 plays a crucial role in lactose induction of cellulase genes, either as a lactose transporter or a cellulose sensor [46]. The absence of crt1 abolished cellulase gene expression, being essential in cellulase gene induction independent of intracellular sugar delivery [47]. In $P$. echinulatum $2 \mathrm{HH}$, crt1 was also identified as orthologous to PECH_005610.

In $N$. crassa, CDT1 and CDT2 present dual function, acting as cellodextrin transporters and also holding a key role as cellulose signaling sensors, involved in the induction of cellulases. Still in $N$. crassa, CLP1 is a putative cellodextrin transporter-like protein that is a critical component of cellulase induction pathway. Although CLP1 protein cannot transport cellodextrin, this signaling sensor may suppress cellulase induction. The co-disruption of $c d t 2$ and $\operatorname{clp} 1$ enhanced 6.9-fold the cellulase production with cellobiose induction in the strain $\Delta 3 \beta \mathrm{G}[20]$. In $P$. echinulatum $2 \mathrm{HH}$, clp 1 was identified as orthologous to PECH_007291, while $c d t 1$ is orthologous to PECH_005610 and cdt2 is orthologous to PECH_004467. In addition to the five orthologs listed so far, six more putative cellodextrin transporters and/or sensors were mapped in P. echinulatum 2HH: PECH_007978, PECH_001261, PECH_002010, PECH_008603, PECH_005239, PECH_003597. These transporters lack reviewed orthologs in related fungi, demanding experimental studies to clarify their roles in $P$. echinulatum $2 \mathrm{HH}$ cellulase induction.

Following the tree counterclockwise, Clade 2 carries mainly pentose and glycerol transporters, containing ten STs of $P$. echinulatum $2 \mathrm{HH}$ and twenty-one STs of $A$. niger, as well as two pentose transporters XAT1 and AN25 of $N$. crassa, the first with specificity for $\mathrm{D}$-xylose and L-arabinose and the second is a D-xylosespecific transporter [48]. Besides that, it carries glycerol transporter (MfsA) of Aspergillus fumigatus [49]. 
Transporters expressed by filamentous fungi can often transport more than one type of sugar. For example, $A$. nidulans transporter $\mathrm{XtrD}$ is able to transport xylose, glucose and several other monosaccharides, whereas $T$. reesei STP1 is involved in glucose and cellobiose uptake. In T. reesei, disruption of stp1 comprised major cellulase and hemicellulase genes induction on cellobiose but not on sophorose [47]. In P. echinulatum 2HH, stp1 was identified as orthologous to PECH_001072.

Clade 3 contains diverse pentose and hexose transporters including three STs of $P$. echinulatum $2 \mathrm{HH}$ and L-arabinose LAT1 of $N$. crassa [50], D-xylose XltC of $A$. niger [51], hexose hxtA of $A$. nidulans [52], Dglucose MstF of $A$. niger [53], and D-glucose HXT1 of T. reesei [54]. Clade 4 enclose D-xylose transporters of A. niger and T. reesei [51], in addition to four STs of $P$. echinulatum $2 \mathrm{HH}$. Following, Clade 5 contains quinic acid transporters $[55,56]$ and D-galacturonic acid transporters GatA of $A$. niger [57] and GalA of $N$. crassa [58], enclosing also eight STs of $P$. echinulatum $2 \mathrm{HH}$.

Clade 6 includes seven STs of P. echinulatum 2HH, one pentose transporter XYT-1 [48], one glucose sensor RCO-3 [59]. It also comprises D-glucose transporters including Hgt-1/-2 and Glt1 [60] of $N$. crassa and some other Aspergillus species [mstA, mstC, mstD, mstE, mstG and mstH of A. nidulans and A. niger] [22]. Clade 7 comprises nine STs of $P$. echinulatum $2 \mathrm{HH}$, ten STs of $A$. niger [22] and one known maltose permease of $A$. oryzae [61]. Lastly, Clade 8 includes nine inositol and fructose transporters of $A$. niger [22] and five STs of $P$. echinulatum $2 \mathrm{HH}$.

In summary, our phylogenetic analysis, including sugar transportome of $P$. echinulatum $2 \mathrm{HH}$, follows the same classification observed in A. niger [22]. Eight major families of STs with specificity to different groups of sugar molecules were identified, involving hexoses, pentoses, di-/oligosaccharides, and galacturonic/quinic acid. Furthermore, we also identified 11 STs of $P$. echinulatum $2 \mathrm{HH}$ and 9 known cellodextrin and lactose transporters from related fungi, which are grouped in a specific clade in our phylogenetic analysis. Of these 11 STs of P. echinulatum 2HH, 5 STs correspond to orthologous reported in literature of the related fungi, which are proven to affect the induction of cellulolytic enzymes. These results suggest that $P$. echinulatum $2 \mathrm{HH}$ diversity and specificity of STs are consistent to other cellulase producers. The putative STs provide new insights into metabolism and nutritional behavior of P. echinulatum 2HH. Finally, the genes highlighted with blue stars in the tree comprise the basement to comprehend the role of cellobiose induction on the cellulolytic expression mechanisms of $P$. echinulatum $2 \mathrm{HH}$. These gene targets can be applied to different industrial processes and represent an important tool to engineer $P$. echinulatum $2 \mathrm{HH}$ for the biofuel industry.

In the genomic analyses we found out various novel features of the lignocellulolytic enzyme system of $P$. echinulatum $2 \mathrm{HH}$. The CAZyome characterization exhibits the outstanding repertoire of enzymes involved in the degradation of lignocellulolytic biomass offered by $P$. echinulatum $2 \mathrm{HH}$. In fact, the genes that constitute the cellulolytic enzyme system of $2 \mathrm{HH}$ strain are predominantly orthologs to the cellulolytic enzyme system of $P$. oxalicum 114-2, revealing the phylogenetic proximity of these filamentous fungi. Cellulolytic activities of AA16, GH5-4 and GH45 deserve attention when it comes to understanding their roles in the cellulose degradation system of $P$. echinulatum $2 \mathrm{HH}$ and $P$. oxalicum $114-2$, considering that these encoding genes comprehend the main differences in the cellulolytic complexes, when both are compared to the commercial producers. Both cellulolytic systems include a LPMO-type enzyme of the AA16 family, which acts on cellulose with oxidative cleavage at the $\mathrm{C} 1$ position of the glucose unit, described for the first time in these fungi.

Besides the similarities, we also highlight the singularities in the lignocellulolytic enzyme system of $P$. echinulatum $2 \mathrm{HH}$. Considering CAZymes as evolutionary markers, we compared $P$. echinulatum $2 \mathrm{HH}$ to $P$. oxalicum 114-2, reinforcing the previous reported hypothesis of environment-specific adaptations in $P$. echinulatum $2 \mathrm{HH}$ during a potential long-term mutualistic symbiosis with $A$. punctatum larvae. We suggest that adaptations to the symbiotic environment associated to the larvae restricted diet could potentially explain some differences in the gene composition of enzymes required to degrade wood. Major differences include: i) fewer encoding-genes for oxidoreductases related to degradation of lignin in P. echinulatum $2 \mathrm{HH}$; and ii) functional genes with low transcription levels corresponding to cellulolytic enzymes in $P$. oxalicum 114-2, whose orthologs were absent or identified as pseudogene in $P$. echinulatum $2 \mathrm{HH}$. However, our results are not conclusive and the potential long-term mutualistic symbiosis persists as a hypothesis.

In addition to the CAZyome, we also characterized the sugar transportome of $P$. echinulatum $2 \mathrm{HH}$. Our phylogenetic analysis suggests that $P$. echinulatum $2 \mathrm{HH}$ diversity and specificity of STs are consistent to other enzyme producers, including eight major families of STs with specificity to different groups of sugars. Phylogenetic classification of STs helps to clarify the role of STs regarding the preferred carbon source of $P$. echinulatum 2HH. Furthermore, the phylogenetic analyses of iBGLs and STs enabled the identification of several iBGLs and STs involved in the accumulation of intracellular cellodextrins, bringing about a few candidate target genes for rational engineering of industrial 
strains. Considering the intracellular cyclodextrin accumulation mechanism that plays a key role inducting the expression of cellulolytic enzymes in filamentous fungi by a signalling cascade pathway. Overall, a significant number of putative iBGLs and STs of $P$. echinulatum $2 \mathrm{HH}$ correspond to orthologs reported in the literature of related fungi, which are proven to affect the induction of cellulolytic enzymes. These iBGLs and STs comprise valuable gene targets to understand the mechanisms underlying the regulation of cellulolytic enzymes and to design hypersecreting strains of $P$. echinulatum $2 \mathrm{HH}$.

\section{CONCLUSIONS}

Our results provide important steps into building molecular understanding of $P$. echinulatum $2 \mathrm{HH}$, revealing surprising features related to PBDC, particularly about the cellulolytic enzyme system. Knowledge of CAZys and STs provide valuable instruments for strain improvements for ethanol production, regarding adequate enzymatic balance for the attributes of second-generation feedstocks, such as crop residue of corn or sugar-cane bagasse. Finally, we highlight $P$. echinulatum $2 \mathrm{HH}$ distinguished cellulolytic system, promoting this species as an important biotechnological ally for lignocellulosic biofuel production.

\section{MATERIAL AND METHODS}

Fungal proteomes analyzed

Proteomes of $P$. echinulatum 2HH and S1M29 are available at National Center for Biotechnology Information (NCBI) under the accession numbers WIWU00000000 and WIWV00000000, respectively. The information of the other eleven fungal proteomes used in this study were downloaded from the UniprotKB server for a) $P$. oxalicum 114-2 (UP000019376) [62]; b) P. chrysogenum P2niaD18 (UP000076449); c) P. digitatum Pd1 (UP000009886); d) P. brasilianum MG11 (UP000042958); e) P. subrubescens CBS 132785 (UP000186955); f) A. niger CBS 513.88 (UP000006706); g) A. nidulans FGSC A4 (UP000000560); h) A. oryzae RIB40 (UP000006564); i) A. fumigatus Af293 (UP000002530); j) T. reesei Qm6a (UP000008984); and k) N. crassa OR74A (UP000001805).

\section{CAZyome annotation}

Recently, the systematic analysis of bacterial [63] and fungal [64] genomes highlighted the distribution and the variability of enzymes involved in polysaccharide degradation. These approaches provide a framework to investigate CAZymes diversity, and to identify new enzymes with potential for the biopolymer degradation industry.
In this study we used CAZy database (07/31/2019), which comprises full-length protein sequences included in CAZyDB, downloaded on 30/08/2019 from http://bcb.unl.edu/dbCAN2/download/Databases/. In addition, we used dbCAN HMMdb release 8.0 (08/08/2019), comprehending 641 HMMs of CAZymes (421 family HMMs +3 cellulosome HMMs +217 subfamily HMMs), data based on CAZyDB released on $07 / 26 / 2019$. Two approaches were combined in order to improve the CAZyome annotation accuracy: (i) running BLASTp (v2.7.1+) [65] against the protein sequences included in the CAZyDB (07/31/2019). All putative protein sequences of $P$. echinulatum were first compared to the full-length protein sequences of CAZyDB by running BLASTP. Query sequences that produced an e-value $<10-6$ and aligned over at least $95 \%$ with a protein in CAZyDB with $>50 \%$ identity were assigned to the same family as the subject sequence; (ii) running dbCAN2 [66] server against the HMMs included in the HMMdb release 8.0. All putative protein sequences of $P$. echinulatum were also subjected to dbCAN2 searches against HMMdb using specific HMMs for each CAZy module family. dbCAN2 combine three tools outputs from HMMER cut-off (e-value $<1 \mathrm{e}-15$, coverage $>0.35)$, DIAMOND cut-off (e-Value $<1 \mathrm{e}-102)$ and Hotpep cut-off (frequency $>6.0$, hits $>2.6$ ).

In addition to dbCAN2 predictions, InterPro [67], PROSITE [68] and Pfam [69] were also used to improve accuracy of carbohydrate binding modules assignment. To perform a realiable CAZyome annotation is not a simple task, especially when dealing with a novel species. For dbCAN authors [66], the reliability of their tool depends on CAZy predictions by more than one tool. Our experience in this annotation suggests that the two approaches used in this study are complementary and relevant to assign CAZy families, although they are not yet sufficient to assign putative protein products. Along these lines, all putative CAZymes sequences were also subjected to manual curation which involved BLASTp searches against UniProtKB/SwissProt/TrEMBL [70] and orthologous inspection from related fungi to assign function to each CAZyme. Orthologous groups were found by searches using ProteinOrtho (V5.16b) [71].

\section{Comparison of Plant Biomass Degrading CAZymes (PBDC)}

In order to explore the ability of the twelve investigated filamentous fungi ( $P$. echinulatum and the eleven related fungi) to degrade plant biomass, all encoded protein sequences (Additional file A02) were first subjected to dbCAN2 [66] server against HMMdb release 8.0 using specific HMM models for each CAZy module family using default cut-off values (previous detailed 
in P. echinulatum CAZyome annotation). Next, CAZy families involved in degradation of plant biomass, previously described in [31], were used to classify all putative CAZymes predicted by dbCAN2. Then, all putative CAZymes sequences were subjected to SignalP Server (v5.0) [72] to predict the presence and location of signal peptide cleavage sites. Finally, ggplot2 [73] was used to plot all charts.

CAZymes as evolutionary markers

All proteomes detailed in the section Fungal proteomes analyzed were used to find orthologous groups in whole genome-wide searches using ProteinOrtho (V5.16b) [71].

\section{Phylogenetic analysis of iBGLs}

The proteomes of $P$. echinulatum and the other eleven related fungi were investigated to find iBGL protein sequences. Those belonging to GH1 and GH3 families were added to separate datasets. BGLs from $A$. thaliana $[74,75]$ were used as outgroups in the phylogenetic analyses. Detailed information about these datasets are available in the Additional file A03.

Each collected iBGL dataset was aligned using the protein alignment tool M-Coffee [76], with default parameters. The CIPRES Science Gateway (v3.3) [77] was used to perform RAxML-HPC2 (v8.2.8) [78]. The workflow analysis was used for bootstrap support (BS), setting PROTGAMMAWAG, executing Maximum Likelihood search and thereafter a thorough bootstrap with 1000 iterations, for each dataset (GH1 and GH3). The resulting trees were visualized and configured using iTOL [79].

\section{Identification of STs}

To assess the diversity of STs, the ST domain (PF00083) profile extracted from PFAM database [69] was used to search against the proteomes of $P$. echinulatum and the other eleven related fungi with hmmsearch (v3.1b2) [80], choosing hmmsearch score $\geq 238$ as cutoff $[22]$.

\section{Phylogenetic analysis of STs}

A dataset was created including 64 putative STs of $P$. echinulatum, 85 putative ST sequences of $A$. niger CBS 513.88 [22], as well as, 44 fungal $\mathrm{ST}$ protein sequences of related fungi (Only protein sequences reviewed or referenced in previous studies were included for better tree visualization). In addition, $7 \mathrm{ST}$ from $A$. thaliana [81] were used as outgroup in the phylogenetic analysis. Detailed information about this dataset containing 200 ST protein sequences is available in the Additional file A03.

The collected ST sequences were aligned using TMCoffee [82], a transmembrane protein alignment tool.
The parameter sequence type was set as transmembrane and the parameter homology extension was set as UniRef100. The CIPRES Science Gateway (v3.3) [77] was used to perform RAxML-HPC2 (v8.2.8) [78]. The workflow analysis for ST dataset was performed to obtain bootstrap support (BS), setting PROTGAMMAWAG, executing Maximum Likelihood search and thereafter a thorough bootstrap with 500 iterations. The resulting tree was visualized and configured using iTOL [79].

\section{Ethics declarations}

Ethics approval and consent to participate

Not applicable.

\section{Consent for publication \\ Not applicable.}

\section{Competing interests}

The authors declare that they have no competing interests.

\section{Funding}

We are grateful to the Coordination for the Improvement of Higher Education Personnel (CAPES) for the PhD scholarship (88887.158496/2017-00 to Lenz, A.R.). This research was supported by grants from CAPES (3255/2013), the National Council for Scientific and Technological Development (CNPq) (472153/20137) and Dirección General de Asuntos del Personal Académico-Universidad Nacional Autónoma de México (UNAM) (IN-209620). Camassola, M. and Dillon, A.J.P. are $\mathrm{CNPq}$ Research Fellowship.

\section{Author's contributions}

The authors contributed equally to this work. All authors read and approved the final manuscript.

\section{Acknowledgements}

We are thankful to CAPES, Bahia State University (UNEB) and University of Caxias do Sul (UCS), especially to UNEB for the leave of absence $(3.145 / 2016$ to Lenz, A.R.).

\section{Availability of data and material}

All data generated or analyzed during this study are included in additional files or available in public databases. Genomic data of $P$. echinulatum are available in NCBI database. The $2 \mathrm{HH}$ wild-type data were deposited under the accession numbers PRJNA520890 (BioProject); SRX6631912, SRX6631913 and SRX6631914 (SRA); and WIWU00000000 (WGS). The S1M29 mutant data were deposited under the accession numbers PRJNA521489 (BioProject); SRX6631956, SRX6631957 and SRX6631958 (SRA); and WIWV00000000 (WGS). 


\section{List of abbreviations}

AA: Auxiliary Activity CBM: Carbohydrate Binding Module CE: Carbohydrate Esterase CAZy: CarbohydrateActive Enzyme CDH: Cellobiose dehydrogenase EGL: Endoglucanase GH: Glycoside Hydrolase GT: Glycosyl Transferase BGL: $\beta$-glucosidase iBGL: intracellular $\beta$-glucosidase LPMO: Lytic polysaccharide monooxygenase MFS: Major facilitator superfamily PBDC: Plant Biomass Degrading CAZymes PL: Polysaccharide Lyase SRA: Sequence Read Archives ST: Sugar Transporter WGS: Whole genome sequences

\footnotetext{
Author details

${ }^{1}$ Laboratório de Bioinformática e Biologia Computacional, Instituto de Biotecnologia, Universidade de Caxias do Sul (UCS), Rua Francisco Getúlio Vargas, 1130, 95070-560, Caxias Do Sul, RS, BR. ${ }^{2}$ Laboratório de Enzimas e Biomassas, Instituto de Biotecnologia, Universidade de Caxias do Sul (UCS), Rua Francisco Getúlio Vargas, 1130, 95070-560, Caxias Do Sul, RS, BR. ${ }^{3}$ Departmento de Ciências Exatas e da Terra, Universidade do Estado da Bahia (UNEB), Rua Silveira Martins, 2555, 41150-000, Salvador, BA, BR. ${ }^{4}$ Instituto de Investigaciones en Matemáticas Aplicadas y en Sistemas. Unidad Académica Yucatán. Universidad Nacional Autónoma de México (UNAM), C.P. 97302, Mérida, Yucatán, MX.
}

\section{References}

1. Dalena, F., Senatore, A., lulianelli, A., Di Paola, L., Basile, M., Basile, A.: Chapter 2 - ethanol from biomass: Future and perspectives. In: Basile, A., lulianelli, A., Dalena, F., Veziroğlu, T.N. (eds.) Ethanol, pp. 25-59. Elsevier, Amsterdam, The Netherlands (2019). doi:10.1016/b978-0-12-811458-2.00002-x

2. Vaishnav, N., Singh, A., Adsul, M., Dixit, P., Sandhu, S.K., Mathur, A., Puri, S.K., Singhania, R.R.: Penicillium: The next emerging champion for cellulase production. Bioresource Technology Reports 2, 131-140 (2018). doi:10.1016/j.biteb.2018.04.003

3. Ribeiro, D.A., Cota, J., Alvarez, T.M., Brüchli, F., Bragato, J., Pereira, B.M.P., Pauletti, B.A., Jackson, G., Pimenta, M.T.B., Murakami, M.T., Camassola, M., Ruller, R., Dillon, A.J.P., Pradella, J.G.C., Paes Leme, A.F., Squina, F.M.: The Penicillium echinulatum Secretome on Sugar Cane Bagasse. PLoS ONE 7(12), 50571-50571 (2012). doi:10.1371/journal.pone.0050571

4. Camassola, M., Dillon, A.J.P.: Steam-Exploded Sugar Cane Bagasse for On-Site Production of Cellulases and Xylanases by Penicillium echinulatum. Energy \& Fuels 26(8), 5316-5320 (2012). doi:10.1021/ef3009162

5. Scholl, A.L., Menegol, D., Pitarelo, A.P., Fontana, R.C., Filho, A.Z., Ramos, L.P., Dillon, A.J.P., Camassola, M.: Ethanol production from sugars obtained during enzymatic hydrolysis of elephant grass (Pennisetum purpureum, Schum.) pretreated by steam explosion. Bioresource Technology 192, 228-237 (2015). doi:10.1016/j.biortech.2015.05.065

6. Menegol, D., Fontana, R.C., Dillon, A.J.P., Camassola, M.: Second-generation ethanol production from elephant grass at high total solids. Bioresource Technology 211, 280-290 (2016). doi:10.1016/j.biortech.2016.03.098

7. Schneider, W.D.H., Gonçalves, T.A., Uchima, C.A., Couger, M.B., Prade, R., Squina, F.M., Dillon, A.J.P., Camassola, M.: Penicillium echinulatum secretome analysis reveals the fungi potential for degradation of lignocellulosic biomass. Biotechnology for Biofuels 9(1), 66 (2016). doi:10.1186/s13068-016-0476-3

8. Schneider, W.D.H., Gonçalves, T.A., Uchima, C.A., dos Reis, L., Fontana, R.C., Squina, F.M., Dillon, A.J.P., Camassola, M.: Comparison of the production of enzymes to cell wall hydrolysis using different carbon sources by Penicillium echinulatum strains and its hydrolysis potential for lignocelullosic biomass. Process Biochemistry 66, 162-170 (2018). doi:10.1016/j.procbio.2017.11.004

9. Hyde, K.D., Xu, J., Rapior, S., Jeewon, R., Lumyong, S., Niego, A.G.T., Abeywickrama, P.D., Aluthmuhandiram, J.V.S., Brahamanage, R.S., Brooks, S., Chaiyasen, A., Chethana, K.W.T., Chomnunti, P.,
Chepkirui, C., Chuankid, B., de Silva, N.I., Doilom, M., Faulds, C., Gentekaki, E., Gopalan, V., Kakumyan, P., Harishchandra, D., Hemachandran, H., Hongsanan, S., Karunarathna, A., Karunarathna, S.C., Khan, S., Kumla, J., Jayawardena, R.S., Liu, J.K., Liu, N., Luangharn, T., Macabeo, A.P.G., Marasinghe, D.S., Meeks, D., Mortimer, P.E., Mueller, P., Nadir, S., Nataraja, K.N.,

Nontachaiyapoom, S., O'Brien, M., Penkhrue, W., Phukhamsakda, C., Ramanan, U.S., Rathnayaka, A.R., Sadaba, R.B., Sandargo, B., Samarakoon, B.C., Tennakoon, D.S., Siva, R., Sriprom, W., Suryanarayanan, T.S., Sujarit, K., Suwannarach, N., Suwunwong, T., Thongbai, B., Thongklang, N., Wei, D., Wijesinghe, S.N., Winiski, J., Yan, J., Yasanthika, E., Stadler, M.: The amazing potential of fungi: 50 ways we can exploit fungi industrially. Fungal Diversity 97(1), 1-136 (2019). doi:10.1007/s13225-019-00430-9

10. Druzhinina, I.S., Kubicek, C.P.: Genetic engineering of Trichoderma reesei cellulases and their production. Microbial Biotechnology 10(6), 1485-1499 (2017). doi:10.1111/1751-7915.12726

11. Wheeler, Q., Crowson, R.A.: The Biology of the Coleoptera. Systematic Zoology 31(3), 342 (1982). doi:10.2307/2413243

12. Glass, N.L., Schmoll, M., Cate, J.H.D., Coradetti, S.: Plant Cell Wall Deconstruction by Ascomycete Fungi. Annual Review of Microbiology 67(1), 477-498 (2013). doi:10.1146/annurev-micro-092611-150044

13. Panchapakesan, A., Shankar, N.: Fungal Cellulases: An Overview. New and Future Developments in Microbial Biotechnology and Bioengineering: Microbial Cellulase System Properties and Applications, 9-18 (2016). doi:10.1016/B978-0-444-63507-5.00002-2

14. Lombard, V., Golaconda Ramulu, H., Drula, E., Coutinho, P.M., Henrissat, B.: The carbohydrate-active enzymes database (CAZy) in 2013. Nucleic Acids Research 42(D1), 490-495 (2014). doi:10.1093/nar/gkt1178

15. Rytioja, J., Hildén, K., Yuzon, J., Hatakka, A., de Vries, R.P., Mäkelä, M.R.: Plant-Polysaccharide-Degrading Enzymes from Basidiomycetes. Microbiology and Molecular Biology Reviews 78(4), 614-649 (2014). doi: $10.1128 / \mathrm{mmbr} .00035-14$

16. Filiatrault-Chastel, C., Navarro, D., Haon, M., Grisel, S., Herpoël-Gimbert, I., Chevret, D., Fanuel, M., Henrissat, B., Heiss-Blanquet, S., Margeot, A., Berrin, J.G.: AA16, a new lytic polysaccharide monooxygenase family identified in fungal secretomes. Biotechnology for Biofuels 12(1), 55 (2019). doi:10.1186/s13068-019-1394-y

17. Hu, J., Tian, D., Renneckar, S., Saddler, J.N.: Enzyme mediated nanofibrillation of cellulose by the synergistic actions of an endoglucanase, lytic polysaccharide monooxygenase (LPMO) and xylanase. Scientific Reports 8(1), 3195 (2018). doi:10.1038/s41598-018-21016-6

18. Aro, N., Pakula, T., Penttilä, M.: Transcriptional regulation of plant cell wall degradation by filamentous fungi. FEMS Microbiology Reviews 29(4), 719-739 (2005). doi:10.1016/j.femsre.2004.11.006

19. Yao, G., Wu, R., Kan, Q., Gao, L., Liu, M., Yang, P., Du, J., Li, Z., $\mathrm{Qu}, \mathrm{Y}$.: Production of a high-efficiency cellulase complex via $\beta$-glucosidase engineering in Penicillium oxalicum. Biotechnology for Biofuels 9(1), 78 (2016). doi:10.1186/s13068-016-0491-4

20. Cai, P., Wang, B., Ji, J., Jiang, Y., Wan, L., Tian, C., Ma, Y.: The putative cellodextrin transporter-like protein CLP1 is involved in cellulase induction in Neurospora crassa. Journal of Biological Chemistry 290(2), 788-796 (2015). doi:10.1074/jbc.M114.609875

21. Gonçalves, C., Coelho, M.A., Salema-Oom, M., Gonçalves, P.: Stepwise Functional Evolution in a Fungal Sugar Transporter Family. Molecular Biology and Evolution 33(2), 352-366 (2015) doi:10.1093/molbev/msv220

22. Peng, M., Aguilar-Pontes, M.V., de Vries, R.P., Mäkelä, M.R.: In silico analysis of putative sugar transporter genes in Aspergillus niger using phylogeny and comparative transcriptomics. Frontiers in Microbiology 9(MAY), 1045 (2018). doi:10.3389/fmicb.2018.01045

23. Dos Reis, T.F., De Lima, P.B.A., Parachin, N.S., Mingossi, F.B., De Castro Oliveira, J.V., Ries, L.N.A., Goldman, G.H.: Identification and characterization of putative xylose and cellobiose transporters in Aspergillus nidulans. Biotechnology for Biofuels 9(1), 204 (2016). doi:10.1186/s13068-016-0611-1

24. Rubini, M.R., Dillon, A.J.P., Kyaw, C.M., Faria, F.P., Poças-Fonseca, M.J., Silva-Pereira, I.: Cloning, characterization and heterologous 
expression of the first Penicillium echinulatum cellulase gene. Journal of Applied Microbiology 108(4), 1187-1198 (2010). doi:10.1111/j.1365-2672.2009.04528.x

25. Liu, G., Qin, Y., Hu, Y., Gao, M., Peng, S., Qu, Y.: An endo-1,4- $\beta$-glucanase $\mathrm{PdCe} 5 \mathrm{C}$ from cellulolytic fungus Penicillium decumbens with distinctive domain composition and hydrolysis product profile. Enzyme and Microbial Technology 52(3), 190-195 (2013). doi:10.1016/j.enzmictec.2012.12.009

26. Georgelis, N., Nikolaidis, N., Cosgrove, D.J.: Biochemical analysis of expansin-like proteins from microbes. Carbohydrate Polymers $\mathbf{1 0 0}$, 17-23 (2014). doi:10.1016/j.carbpol.2013.04.094

27. Liu, G., Zhang, L., Qin, Y., Zou, G., Li, Z., Yan, X., Wei, X., Chen, M., Chen, L., Zheng, K., Zhang, J., Ma, L., Li, J., Liu, R., Xu, H., Bao, X., Fang, X., Wang, L., Zhong, Y., Liu, W., Zheng, H., Wang, S., Wang, C., Xun, L., Zhao, G.P., Wang, T., Zhou, Z., Qu, Y.: Long-term strain improvements accumulate mutations in regulatory elements responsible for hyper-production of cellulolytic enzymes. Scientific Reports 3, 1569 (2013). doi:10.1038/srep01569

28. Albalat, R., Cañestro, C.: Evolution by gene loss. Nature Reviews Genetics 17(7), 379-391 (2016). doi:10.1038/nrg.2016.39

29. Nagy, L.G., Riley, R., Tritt, A., Adam, C., Daum, C., Floudas, D., Sun, H., Yadav, J.S., Pangilinan, J., Larsson, K.H., Matsuura, K., Barry, K., Labutti, K., Kuo, R., Ohm, R.A., Bhattacharya, S.S., Shirouzu, T., Yoshinaga, Y., Martin, F.M., Grigoriev, I.V., Hibbett, D.S.: Comparative genomics of early-diverging mushroom-forming fungi provides insights into the origins of lignocellulose decay capabilities. Molecular Biology and Evolution 33(4), 959-970 (2016). doi:10.1093/molbev/msv337

30. Brissos, V., Tavares, D., Sousa, A.C., Robalo, M.P., Martins, L.O.: Engineering a Bacterial DyP-Type Peroxidase for Enhanced Oxidation of Lignin-Related Phenolics at Alkaline pH. ACS Catalysis 7(5), 3454-3465 (2017). doi:10.1021/acscatal.6b03331

31. Peng, M., Dilokpimol, A., Mäkelä, M.R., Hildén, K., Bervoets, S., Riley, R., Grigoriev, I.V., Hainaut, M., Henrissat, B., de Vries, R.P., Granchi, Z.: The draft genome sequence of the ascomycete fungus Penicillium subrubescens reveals a highly enriched content of plant biomass related CAZymes compared to related fungi. Journal of Biotechnology 246, 1-3 (2017). doi:10.1016/j.jbiotec.2017.02.012

32. Daly, P., van Munster, J.M., Kokolski, M., Sang, F., Blythe, M.J., Malla, S., Velasco de Castro Oliveira, J., Goldman, G.H., Archer, D.B.: Transcriptomic responses of mixed cultures of ascomycete fungi to lignocellulose using dual RNA-seq reveal inter-species antagonism and limited beneficial effects on CAZyme expression. Fungal Genetics and Biology 102, 4-21 (2017). doi:10.1016/j.fgb.2016.04.005

33. Li, C., Lin, F., Li, Y., Wei, W., Wang, H., Qin, L., Zhou, Z., Li, B., Wu, F., Chen, Z.: A $\beta$-glucosidase hyper-production Trichoderma reesei mutant reveals a potential role of cel3D in cellulase production. Microbial Cell Factories 15(1), 151 (2016). doi:10.1186/s12934-016-0550-3

34. Shida, Y., Yamaguchi, K., Nitta, M., Nakamura, A., Takahashi, M., Kidokoro, S.I., Mori, K., Tashiro, K., Kuhara, S., Matsuzawa, T., Yaoi, K., Sakamoto, Y., Tanaka, N., Morikawa, Y., Ogasawara, W.: The impact of a single-nucleotide mutation of bgl2 on cellulase induction in a Trichoderma reesei mutant. Biotechnology for Biofuels 8(1), 230 (2015). doi:10.1186/s13068-015-0420-y

35. Li, J., Liu, G., Chen, M., Li, Z., Qin, Y., Qu, Y.: Cellodextrin transporters play important roles in cellulase induction in the cellulolytic fungus Penicillium oxalicum. Applied Microbiology and Biotechnology 97(24), 10479-10488 (2013). doi:10.1007/s00253-013-5301-3

36. Zhou, Q., Xu, J., Kou, Y., Lv, X., Zhang, X., Zhao, G., Zhang, W., Chen, G., Liu, W.: Differential involvement of $\beta$-glucosidases from Hypocrea jecorina in rapid induction of cellulase genes by cellulose and cellobiose. Eukaryotic Cell 11(11), 1371-1381 (2012). doi:10.1128/EC.00170-12

37. Xu, J., Zhao, G., Kou, Y., Zhang, W., Zhou, Q., Chen, G., Liu, W.: Intracellular $\beta$-glucosidases CEL1a and CEL1b are essential for cellulase induction on lactose in Trichoderma reesei. Eukaryotic Cell 13(8), 1001-1013 (2014). doi:10.1128/EC.00100-14

38. Zou, G., Jiang, Y., Liu, R., Zhu, Z., Zhou, Z.: The putative $\beta$-glucosidase BGL3I regulates cellulase induction in Trichoderma reesei. Biotechnology for Biofuels 11(1), 314 (2018) doi:10.1186/s13068-018-1314-6

39. Qin, L., Jiang, X., Dong, Z., Huang, J., Chen, X.: Identification of two integration sites in favor of transgene expression in Trichoderma reesei. Biotechnology for Biofuels 11(1), 142 (2018). doi:10.1186/s13068-018-1139-3

40. Znameroski, E.A., Coradetti, S.T., Roche, C.M., Tsai, J.C., lavarone, A.T., Cate, J.H.D., Glass, N.L.: Induction of lignocellulose-degrading enzymes in Neurospora crassa by cellodextrins. Proceedings of the National Academy of Sciences of the United States of America 109(16), 6012-6017 (2012). doi:10.1073/pnas.1118440109

41. Wu, W., Kasuga, T., Xiong, X., Ma, D., Fan, Z.: Location and contribution of individual $\beta$-glucosidase from Neurospora crassa to total $\beta$-glucosidase activity. Archives of Microbiology 195(12), 823-829 (2013). doi:10.1007/s00203-013-0931-5

42. Li, Z., Yao, G., Wu, R., Gao, L., Kan, Q., Liu, M., Yang, P., Liu, G., Qin, Y., Song, X., Zhong, Y., Fang, X., Qu, Y.: Synergistic and Dose-Controlled Regulation of Cellulase Gene Expression in Penicillium oxalicum. PLoS Genetics 11(9), 1005509-1005509 (2015). doi:10.1371/journal.pgen.1005509

43. de Vries, R.P., Riley, R., Wiebenga, A., Aguilar-Osorio, G., Amillis, S., Uchima, C.A., Anderluh, G., Asadollahi, M., Askin, M., Barry, K., Battaglia, E., Bayram, Ö., Benocci, T., Braus-Stromeyer, S.A., Caldana, C., Cánovas, D., Cerqueira, G.C., Chen, F., Chen, W., Choi, C., Clum, A., dos Santos, R.A.C., de Lima Damásio, A.R., Diallinas, G., Emri, T., Fekete, E., Flipphi, M., Freyberg, S., Gallo, A., Gournas, C., Habgood, R., Hainaut, M., Harispe, M.L., Henrissat, B., Hildén, K.S., Hope, R., Hossain, A., Karabika, E., Karaffa, L., Karányi, Z., Kraševec, N., Kuo, A., Kusch, H., LaButti, K., Lagendijk, E.L., Lapidus, A., Levasseur, A., Lindquist, E., Lipzen, A., Logrieco, A.F., MacCabe, A., Mäkelä, M.R., Malavazi, I., Melin, P., Meyer, V., Mielnichuk, N., Miskei, M., Molnár, Á.P., Mulé, G., Ngan, C.Y., Orejas, M., Orosz, E., Ouedraogo, J.P., Overkamp, K.M., Park, H.S., Perrone, G., Piumi, F., Punt, P.J., Ram, A.F.J., Ramón, A., Rauscher, S., Record, E., Riaño-Pachón, D.M., Robert, V., Röhrig, J., Ruller, R., Salamov, A., Salih, N.S., Samson, R.A., Sándor, E., Sanguinetti, M., Schütze, T., Sepčić, K., Shelest, E., Sherlock, G., Sophianopoulou, V., Squina, F.M., Sun, H., Susca, A., Todd, R.B., Tsang, A., Unkles, S.E., van de Wiele, N., van Rossen-Uffink, D., de Castro Oliveira, J.V., Vesth, T.C., Visser, J., Yu, J.H., Zhou, M., Andersen, M.R., Archer, D.B., Baker, S.E., Benoit, I., Brakhage, A.A., Braus, G.H., Fischer, R., Frisvad, J.C., Goldman, G.H., Houbraken, J., Oakley, B., Pócsi, I., Scazzocchio, C., Seiboth, B., VanKuyk, P.A., Wortman, J., Dyer, P.S., Grigoriev, I.V.: Comparative genomics reveals high biological diversity and specific adaptations in the industrially and medically important fungal genus Aspergillus. Genome Biology 18(1), 28 (2017). doi:10.1186/s13059-017-1151-0

44. Fekete, E., Orosz, A., Kulcsár, L., Kavalecz, N., Flipphi, M., Karaffa, L.: Characterization of a second physiologically relevant lactose permease gene (lacpB) in aspergillus nidulans. Microbiology (United Kingdom) 162(5), 837-847 (2016). doi:10.1099/mic.0.000267

45. Sehnem, N.T., De Bittencourt, L.R., Camassola, M., Dillon, A.J.P.: Cellulase production by Penicillium echinulatum on lactose. Applied Microbiology and Biotechnology 72(1), 163-167 (2006). doi:10.1007/s00253-005-0251-z

46. Ivanova, C., Bååth, J.A., Seiboth, B., Kubicek, C.P.: Systems Analysis of Lactose Metabolism in Trichoderma reesei Identifies a Lactose Permease That Is Essential for Cellulase Induction. PLoS ONE 8(5), 62631 (2013). doi:10.1371/journal.pone.0062631

47. Zhang, W., Kou, Y., Xu, J., Cao, Y., Zhao, G., Shao, J., Wang, H., Wang, Z., Bao, X., Chen, G., Liu, W.: Two major facilitator superfamily sugar transporters from Trichoderma reesei and their roles in induction of cellulase biosynthesis. Journal of Biological Chemistry 288(46), 32861-32872 (2013). doi:10.1074/jbc.M113.505826

48. Li, J., Lin, L., Li, H., Tian, C., Ma, Y.: Transcriptional comparison of the filamentous fungus Neurospora crassa growing on three major monosaccharides D-glucose, D-xylose and L-arabinose. Biotechnology for Biofuels 7(1), 31 (2014). doi:10.1186/1754-6834-7-31

49. Morton, C.O., Varga, J.J., Hornbach, A., Mezger, M., Sennefelder, H., Kneitz, S., Kurzai, O., Krappmann, S., Einsele, H., Nierman, W.C., Rogers, T.R., Loeffler, J.: The temporal dynamics of differential gene 
expression in Aspergillus fumigatus interacting with human immature dendritic cells in vitro. PLoS ONE 6(1), 16016-16016 (2011). doi:10.1371/journal.pone.0016016

50. Benz, P.J., Chau, B.H., Zheng, D., Bauer, S., Glass, N.L., Somerville, C.R.: A comparative systems analysis of polysaccharide-elicited responses in Neurospora crassa reveals carbon source-specific cellular adaptations. Molecular Microbiology 91(2), 275-299 (2014). doi:10.1111/mmi.12459

51. Sloothaak, J., Tamayo-Ramos, J.A., Odoni, D.I., Laothanachareon, T., Derntl, C., Mach-Aigner, A.R., Martins Dos Santos, V.A.P., Schaap, P.J.: Identification and functional characterization of novel xylose transporters from the cell factories Aspergillus Niger and Trichoderma reesei. Biotechnology for Biofuels 9(1), 148 (2016). doi:10.1186/s13068-016-0564-4

52. Wei, H., Vienken, K., Weber, R., Bunting, S., Requena, N., Fischer, R.: A putative high affinity hexose transporter, hxtA, of Aspergillus nidulans is induced in vegetative hyphae upon starvation and in ascogenous hyphae during cleistothecium formation. Fungal Genetics and Biology 41(2), 148-156 (2004). doi:10.1016/j.fgb.2003.10.006

53. Jørgensen, T.R., VanKuyk, P.A., Poulsen, B.R., Ruijter, G.J.G., Visser, J., Iversen, J.J.L.: Glucose uptake and growth of glucose-limited chemostat cultures of Aspergillus niger and a disruptant lacking MstA, a high-affinity glucose transporter. Microbiology 153(6), 1963-1973 (2007). doi:10.1099/mic.0.2006/005090-0

54. Zhang, W., Cao, Y., Gong, J., Bao, X., Chen, G., Liu, W.: Identification of residues important for substrate uptake in a glucose transporter from the filamentous fungus Trichoderma reesei. Scientific Reports 5(1), 13829 (2015). doi:10.1038/srep13829

55. Whittington, H.A., Grant, S., Roberts, C.F., Lamb, H., Hawkins, A.R.: Identification and isolation of a putative permease gene in the quinic acid utilization (QUT) gene cluster of Aspergillus nidulans. Current Genetics 12(2), 135-139 (1987). doi:10.1007/BF00434668

56. Tang, X., Dong, W., Griffith, J., Nilsen, R., Matthes, A., Cheng, K.B. Reeves, J., Schuttler, H.B., Case, M.E., Arnold, J., Logan, D.A.: Systems biology of the qa gene cluster in Neurospora crassa. PLoS ONE 6(6), 20671 (2011). doi:10.1371/journal.pone.0020671

57. Sloothaak, J., Schilders, M., Schaap, P.J., de Graaff, L.H. Overexpression of the Aspergillus niger GatA transporter leads to preferential use of D-galacturonic acid over D-xylose. AMB Express 4(1), 1-9 (2014). doi:10.1186/s13568-014-0066-3

58. Benz, J.P., Protzko, R.J., Andrich, J.M.S., Bauer, S., Dueber, J.E., Somerville, C.R.: Identification and characterization of a galacturonic acid transporter from Neurospora crassa and its application for Saccharomyces cerevisiae fermentation processes. Biotechnology for Biofuels 7(1), 20 (2014). doi:10.1186/1754-6834-7-20

59. Madi, L., McBride, S.A., Bailey, L.A., Ebbole, D.J.: rco-3, a gene involved in glucose transport and conidiation in Neurospora crassa. Genetics 146(2), 499-508 (1997)

60. Wang, B., Li, J., Gao, J., Cai, P., Han, X., Tian, C.: Identification and characterization of the glucose dual-affinity transport system in Neurospora crassa: Pleiotropic roles in nutrient transport, signaling, and carbon catabolite repression. Biotechnology for Biofuels 10(1), 17 (2017). doi:10.1186/s13068-017-0705-4

61. Hasegawa, S., Takizawa, M., Suyama, H., Shintani, T., Gomi, K.: Characterization and expression analysis of a maltose-utilizing (MAL) cluster in Aspergillus oryzae. Fungal Genetics and Biology 47(1), 1-9 (2010). doi:10.1016/j.fgb.2009.10.005

62. Liu, G., Zhang, L., Wei, X., Zou, G., Qin, Y., Ma, L., Li, J., Zheng, H., Wang, S., Wang, C., Xun, L., Zhao, G.P., Zhou, Z., Qu, Y.: Genomic and Secretomic Analyses Reveal Unique Features of the Lignocellulolytic Enzyme System of Penicillium decumbens. PLoS ONE 8(2), 55185 (2013). doi:10.1371/journal.pone.0055185

63. Talamantes, D., Biabini, N., Dang, H., Abdoun, K., Berlemont, R.: Natural diversity of cellulases, xylanases, and chitinases in bacteria. Biotechnology for Biofuels 9(1), 133 (2016) doi:10.1186/s13068-016-0538-6

64. Berlemont, R.: Distribution and diversity of enzymes for polysaccharide degradation in fungi. Scientific Reports 7(1), 222 (2017). doi:10.1038/s41598-017-00258-w

65. Camacho, C., Coulouris, G., Avagyan, V., Ma, N., Papadopoulos, J., Bealer, K., Madden, T.L.: BLAST+: Architecture and applications.
BMC Bioinformatics 10(1), 421 (2009).

doi:10.1186/1471-2105-10-421

66. Zhang, H., Yohe, T., Huang, L., Entwistle, S., Wu, P., Yang, Z., Busk, P.K., Xu, Y., Yin, Y.: DbCAN2: A meta server for automated carbohydrate-active enzyme annotation. Nucleic Acids Research 46(W1), 95-101 (2018). doi:10.1093/nar/gky418

67. Mitchell, A.L., Attwood, T.K., Babbitt, P.C., Blum, M., Bork, P., Bridge, A., Brown, S.D., Chang, H.Y., El-Gebali, S., Fraser, M.I., Gough, J., Haft, D.R., Huang, H., Letunic, I., Lopez, R., Luciani, A. Madeira, F., Marchler-Bauer, A., Mi, H., Natale, D.A., Necci, M., Nuka, G., Orengo, C., Pandurangan, A.P., Paysan-Lafosse, T., Pesseat, S., Potter, S.C., Qureshi, M.A., Rawlings, N.D., Redaschi, N., Richardson, L.J., Rivoire, C., Salazar, G.A., Sangrador-Vegas, A., Sigrist, C.J.A., Sillitoe, I., Sutton, G.G., Thanki, N., Thomas, P.D., Tosatto, S.C.E., Yong, S.Y., Finn, R.D.: InterPro in 2019: Improving coverage, classification and access to protein sequence annotations. Nucleic Acids Research 47(D1), 351-360 (2019). doi: $10.1093 /$ nar/gky1100

68. Sigrist, C.J.A., De Castro, E., Cerutti, L., Cuche, B.A., Hulo, N., Bridge, A., Bougueleret, L., Xenarios, I.: New and continuing developments at PROSITE. Nucleic Acids Research 41(D1), 344-347 (2013). doi:10.1093/nar/gks1067

69. El-Gebali, S., Mistry, J., Bateman, A., Eddy, S.R., Luciani, A., Potter, S.C., Qureshi, M., Richardson, L.J., Salazar, G.A., Smart, A., Sonnhammer, E.L.L., Hirsh, L., Paladin, L., Piovesan, D., Tosatto, S.C.E., Finn, R.D.: The Pfam protein families database in 2019. Nucleic Acids Research 47(D1), 427-432 (2019). doi:10.1093/nar/gky995

70. Consortium, T.U.: UniProt: a worldwide hub of protein knowledge. Nucleic Acids Research 47(D1), 506-515 (2019) doi: $10.1093 /$ nar/gky1049

71. Lechner, M., Findeiß, S., Steiner, L., Marz, M., Stadler, P.F., Prohaska, S.J.: Proteinortho: Detection of (Co-)orthologs in large-scale analysis. BMC Bioinformatics 12, 124 (2011). doi:10.1186/1471-2105-12-124

72. Almagro Armenteros, J.J., Tsirigos, K.D., Sønderby, C.K., Petersen, T.N., Winther, O., Brunak, S., von Heijne, G., Nielsen, H.: SignalP 5.0 improves signal peptide predictions using deep neural networks. Nature Biotechnology 37(4), 420-423 (2019). doi:10.1038/s41587-019-0036-z

73. Wickham, H.: Ggplot2: Elegant Graphics for Data Analysis vol. 35, 2nd ed. edn. Springer, Cham, Switzerland (2016). doi:10.1007/978-3-319-24277-4

74. Xu, Z., Escamilla-Treviño, L.L., Zeng, L., Lalgondar, M., Bevan, D.R. Winkel, B.S.J., Mohamed, A., Cheng, C.L., Shih, M.C., Poulton, J.E., Esen, A.: Functional genomic analysis of Arabidopsis thaliana glycoside hydrolase family 1. Plant Molecular Biology 55(3), 343-367 (2004). doi:10.1007/s11103-004-0790-1

75. Henrissat, B., Coutinho, P.M., Davies, G.J.: A census of carbohydrate-active enzymes in the genome of Arabidopsis thaliana. Plant Molecular Biology 47(1-2), 55-72 (2001). doi:10.1023/A:1010667012056

76. Wallace, I.M., O'Sullivan, O., Higgins, D.G., Notredame, C.: M-Coffee: Combining multiple sequence alignment methods with T-Coffee. Nucleic Acids Research 34(6), 1692-1699 (2006). doi:10.1093/nar/gkl091

77. Miller, M.A., Pfeiffer, W., Schwartz, T.: Creating the CIPRES Science Gateway for inference of large phylogenetic trees. 2010 Gateway Computing Environments Workshop, GCE 2010, 1-8 (2010). doi:10.1109/GCE.2010.5676129

78. Stamatakis, A.: RAxML version 8: A tool for phylogenetic analysis and post-analysis of large phylogenies. Bioinformatics 30(9), 1312-1313 (2014). doi:10.1093/bioinformatics/btu033

79. Letunic, I., Bork, P.: Interactive Tree Of Life (iTOL) v4: recent updates and new developments. Nucleic acids research 47(W1), 256-259 (2019). doi:10.1093/nar/gkz239

80. Johnson, L.S., Eddy, S.R., Portugaly, E.: Hidden Markov model speed heuristic and iterative HMM search procedure. BMC Bioinformatics 11(1), 431 (2010). doi:10.1186/1471-2105-11-431

81. Büttner, M.: The Arabidopsis sugar transporter (AtSTP) family: An update. Plant Biology 12(SUPPL. 1), 35-41 (2010). doi:10.1111/j.1438-8677.2010.00383.x

82. Floden, E.W., Tommaso, P.D., Chatzou, M., Magis, C., Notredame, 
C., Chang, J.M.: PSI/TM-Coffee: a web server for fast and accurate multiple sequence alignments of regular and transmembrane proteins using homology extension on reduced databases. Nucleic acids research 44(W1), 339-343 (2016). doi:10.1093/nar/gkw300

Figures

Figure 1 Stacked barplot comparing the number of putative proteins classified as PBDC in twelve filamentous fungi. Only proteins containing signal peptide were counted. Distribution of PBDC sums were grouped accordingly to CAZy classes.

Figure 2 Bubble chart comparing the number of putative CAZymes involved in cellulose degradation. ${ }^{*} \mathrm{GH} 3$ count only for $\beta$-glucosidase; Only proteins containing signal peptide were counted.

Figure 3 Phylogenetic classification of iBGLs: a) GH1 and b) GH3 families. The gene names of characterized iBGLs of related fungi are highlighted in bold and in the same colour font of the respective clade; Blue stars are highlighting target genes; Branches with bootstrap values $\geq 70 \%$ were indicated with circles; The gene prefix correspond to the abbreviation of fungal species name $(\mathrm{PECH}=P$. echinulatum, $\mathrm{PDE}=P$. oxalicum, $\mathrm{ANIA}=A$. nidulans, $\mathrm{ANI}=A$. niger, $\mathrm{AFUA}=A$. fumigatus, $\mathrm{NCU}=N$. crassa, $\mathrm{TRIRE}=T$. reesei).

Figure 4 Phylogenetic classification of STs. The gene names of characterized STs of related fungi are highlighted in bold and in the same colour font of the respective clade; Blue stars are highlighting target genes; Branches with bootstrap values $\geq 70 \%$ were indicated with circles; The gene prefix correspond to the abbreviation of fungal species name $(\mathrm{PECH}=P$. echinulatum, $\mathrm{PDE}=P$. oxalicum, $\mathrm{ANIA}=A$. nidulans, $\mathrm{ANI}=$ A. niger, $\mathrm{AO}=A$. oryzae, $\mathrm{AFUA}=A$. fumigatus, $\mathrm{NCU}=N$. crassa, TRIRE $=T$. reesei $)$. 
Tables

Table $1 P$. echinulatum cellulolytic complex encoding genes

\begin{tabular}{|c|c|c|c|c|c|}
\hline $2 \mathrm{HH}$ ID & S1M29 ID & EC number & CAZy family & Full name & Signal Peptide \\
\hline PECH_006365 & PECM_006949 & 3.2.1.91 & GH6 & $1,4-\beta$-D-glucan cellobiohydrolase 3 & Y (18-19) \\
\hline PECH_007386 & PECM_003867 & 3.2.1.91 & $\mathrm{GH} 7$ & $1,4-\beta$-D-glucan cellobiohydrolase 3 & $Y(27-28)$ \\
\hline PECH_008028 & PECM_007794 & 3.2.1.91 & $\mathrm{GH} 7$ & $1,4-\beta$-D-glucan cellobiohydrolase & Y (17-18) \\
\hline PECH_006176 & PECM_002589 & 3.2.1.4 & GH5_4 & Endo-1,4- $\beta$-D-glucanase ${ }^{3}$ & Y (18-19) \\
\hline PECH_009029 & PECM_008781 & 3.2.1.4 & GH5_5 & Endo-1,4- $\beta$-D-glucanase EGL1 1,3 & $\mathrm{Y}(16-17)$ \\
\hline PECH_002030 & PECM_004329 & 3.2.1.4 & GH5_5 & Endo-1,4- $\beta$-D-glucanase ${ }^{3}$ & Y (18-19) \\
\hline PECH_003801 & PECM_006072 & 3.2.1.4 & GH5_5 & Endo- $1,4-\beta$-D-glucanase ${ }^{3}$ & $Y(21-22)$ \\
\hline PECH_001606 & PECM_001417 & 3.2.1.4 & GH5_22 & Endo- $1,4-\beta$-D-glucanase & $\mathrm{N}$ \\
\hline PECH_007371 & PECM_003852 & 3.2.1.4 & $\mathrm{GH} 7$ & Endo-1,4- $\beta$-D-glucanase ${ }^{3}$ & $Y(21-22)$ \\
\hline PECH_003013 & PECM_002481 & 3.2.1.4 & $\mathrm{GH} 12$ & Endo- $1,4-\beta$-D-glucanase & $\mathrm{Y}(16-17)$ \\
\hline PECH_007370 & PECM_003851 & 3.2.1.4 & GH45 & Endo- $1,4-\beta$-D-glucanase 3 & Y (18-19) \\
\hline PECH_006981 & PECM_005047 & - & - & Endo- $1,4-\beta$-D-glucanase ${ }^{2}$ & $\mathrm{~N}$ \\
\hline PECH_004782 & PECM_007582 & 3.2.1.21 & $\mathrm{GH} 3$ & $\beta$-glucosidase & Y (19-20) \\
\hline PECH_002471 & PECM_006691 & 3.2.1.21 & $\mathrm{GH} 3$ & $\beta$-glucosidase & $Y(21-22)$ \\
\hline PECH_005824 & PECM_000560 & 3.2.1.21 & $\mathrm{GH} 3$ & $\beta$-glucosidase & Y (22-23) \\
\hline PECH_003879 & PECM_005646 & 3.2.1.21 & $\mathrm{GH} 3$ & $\beta$-glucosidase & $Y(20-21)$ \\
\hline PECH_007973 & PECM_006421 & 3.2.1.21 & $\mathrm{GH} 3$ & $\beta$-glucosidase & Y (19-20) \\
\hline PECH_004285 & PECM_001151 & 3.2.1.21 & $\mathrm{GH} 3$ & $\beta$-glucosidase & $\mathrm{N}$ \\
\hline PECH_000771 & PECM_004769 & 3.2.1.21 & $\mathrm{GH} 3$ & $\beta$-glucosidase & $\mathrm{N}$ \\
\hline PECH_007289 & PECM_007134 & 3.2.1.21 & $\mathrm{GH} 3$ & $\beta$-glucosidase & $\mathrm{N}$ \\
\hline PECH_003528 & PECM_007417 & 3.2 .1 .21 & $\mathrm{GH} 3$ & $\beta$-glucosidase & $\mathrm{N}$ \\
\hline PECH_002378 & PECM_003008 & 3.2.1.4 & AA9 & Lytic cellulose monooxygenase & Y (22-23) \\
\hline PECH_007161 & PECM_000770 & 3.2.1.4 & AA9 & Lytic cellulose monooxygenase ${ }^{3}$ & Y (18-19) \\
\hline PECH_001644 & PECM_001602 & 3.2.1.4 & AA9 & Lytic cellulose monooxygenase & $\mathrm{Y}(21-22)$ \\
\hline PECH_008064 & PECM_003383 & 3.2.1.4 & AA9 & Lytic cellulose monooxygenase ${ }^{3}$ & Y (19-20) \\
\hline PECH_004020 & PECM_004700 & 1.14 .99 .54 & AA16 & Lytic cellulose monooxygenase (C1-hydroxylating) & $Y(20-21)$ \\
\hline PECH_000306 & PECM_008697 & 1.1.99.18 & AA3_1 & Cellobiose dehydrogenase & Y (22-23) \\
\hline PECH_005234 & PECM_006332 & 1.1.99.18 & AA8 & Cellobiose dehydrogenase (cytochrome) & $\mathrm{N}$ \\
\hline
\end{tabular}

Additional Files

Additional file A01 - CAZyome Annotation of $P$. echinulatum.

Table page A01.1 refers to CAZy families assignments; Table page A01.2 refers to CBM assignments.

Additional file A02 - PBD enzymes assignments in $P$. echinulatum and eleven related fungi.

Table page A02.1 refers to proteomes used in the PBD enzymes analyses; Table page A02.2 refers to PBD enzymes summarized in the twelve fungi; Table page A02.3 refers to cellulolytic enzymes summary in the twelve fungi; Table pages 0 to 11 refers to PBD enzymes assignments in the twelve fungi.

Additional file A03 - Identification and phylogenetic analyses of iBGLs and STs in $P$. echinulatum and eleven related fungi.

Table page A03.1 refers to proteomes used in the iBGLs and STs analyses; Table page A03.2 refers to the summary of iBGLs of GH1 and GH3 families and sugar transporters (PF00083); Table page A03.3 refers to iBGL ortholog groups, highlighting reviewed proteins; Table page A03.4 refers to GH1 protein sequences used in the phylogenetic analysis; Table page A03.5 refers to $\mathrm{GH} 3$ protein sequences used in the phylogenetic analysis; Table page A03.5 refers to GH3 protein sequences used in the phylogenetic analysis; Table page A03.6 refers to protein ids of the sugar transporters (PF00083) identified in the twelve fungi; Table page A03.7 refers to sugar transporter protein sequences used in the phylogenetic analysis. 
Table 2 Distribution of enzymes required to degrade wood in P. echinulatum $2 \mathrm{HH}$ and $P$. oxalicum 114-2

\begin{tabular}{llrr}
\hline Enzyme Family & Activity Related to Wood Degradation & P. oxalicum & $P$. echinulatum \\
\hline Oxidoreductases & & 12 & 11 \\
\hline AA1 & Lignin degradation & 6 & 5 \\
AA2 & Lignin degradation & 3 & 3 \\
DyP (PF04261) & Acting on lignin or lignin derivatives & 0 & 1 \\
HTP (PF01328) & Possible action on lignin derivatives & 3 & 2 \\
\hline CAZys active on polysaccharide main chains & Endoglucanase & 59 & 60 \\
\hline GH5_5 & Endomannanase & 3 & 3 \\
GH5_7 & Cellobiohydrolase & 1 & 2 \\
GH6 & Cellobiohydrolase & 1 & 1 \\
GH7 & Cellulose cleaving oxidoreductase & 3 & 3 \\
AA9 & Cellulose cleaving oxidoreductase & 4 & 4 \\
AA16 & Endoxylanase & 1 & 1 \\
GH10 & Endoglucanase & 3 & 3 \\
GH12 & Pectinase activity & 3 & 3 \\
GH28 & Endoglucanase & 12 & 12 \\
GH45 & Xyloglucanase & 1 & 1 \\
GH74 & $\beta$-glucosidase/ $\beta$-xylosidase & 0 & 0 \\
GH3 & $\alpha$-Arabinofuranosidase/ $\beta$-xylosidase & 14 & 14 \\
GH43 & Esterases (acetyl-xylan, ferruloyl, cinnamoyl) & 14 & 6 \\
\hline Other CAZys related to wood decay & 7 & 4 \\
\hline CE1 & Esterases (acetyl-xylan, ferruloyl, cinnamoyl) & 3 & 2 \\
CE16 & & 3 &
\end{tabular}

